\title{
Onabotulinumtoxin A (ONA-BoNT/A) in the treatment of chronic migraine
}

\author{
Izabela Domitrz ${ }^{1}$, Jarosław Sławek ${ }^{2,3}$, Agnieszka Słowik ${ }^{4}$, Magdalena Boczarska-Jedynak ${ }^{5}$, \\ Adam Stępień ${ }^{6}$, Konrad Rejdak $^{7}$, Jakub Gierczyński ${ }^{8}$, Jacek Rożniecki ${ }^{9}$ \\ ${ }^{1}$ Department of Neurology, Faculty of Medical Sciences, Medical University of Warsaw, Warsaw, Poland \\ ${ }^{2}$ Department of Neurology \& Stroke, St. Adalbert Hospital, “Copernicus” Ltd., Gdansk, Poland \\ ${ }^{3}$ Division of Neurological and Psychiatric Nursing, Faculty of Health Sciences, Medical University of Gdansk, Poland \\ ${ }^{4}$ Department of Neurology, Jagiellonian University, Medical College, Krakow, Poland \\ ${ }^{5}$ Health Institute, Neurology and Restorative Medicine, Oswiecim, Poland \\ ${ }^{6}$ Department of Neurology, Military Institute of Medicine, Warsaw, Poland \\ ${ }^{7}$ Department of Neurology, Medical University of Lublin, Poland \\ ${ }^{8}$ Healthcare Management Institute and Centre of Value Based Healthcare, Lazarski University, Warsaw, Poland \\ ${ }^{9}$ Department of Neurology, Stroke and Neurorehabilitation, Medical University of Lodz, Lodz, Poland
}

\begin{abstract}
Migraine is a common primary headache disease, which reduces quality of life. About $8 \%$ of migraineurs suffer from chronic migraine (CM), which is the most severe and troublesome type. It has been proven that onabotulinumtoxinA (ONA-BoNT/A) significantly improves $C M$, presumably inhibiting the release of calcitonin gene-related peptide (CGRP) and other neurotransmitters from c-fibres endings, and thus decreasing activation of nociceptive pathways and transmission of pain. The aim of this position paper was to assess the place of ONA-BoNT/A for the prophylaxis of CM in adults. The authors have compared the efficacy, safety and tolerance of the toxin to those of classical oral preventive therapies as well as to recently introduced anti-CGRP-pathway monoclonal antibodies. The results of randomised controlled studies of ONA-BoNT/A have been compared to open label (real world practice) trials.

Key words: chronic migraine, botulinum toxin type A, onabotulinumtoxin A, prophylactic treatment, monoclonal antibodies, CGRP (Neurol Neurochir Pol 2022; 56 (1): 39-47)
\end{abstract}

\section{Introduction}

Migraine, as the second leading cause of disability, reduces quality of life, increases the economic burden, and decreases productive capacity [1-4]. Chronic migraine (CM) is the most severe and troublesome type of this disease [5]. According to the International Headache Society, CM is defined as a headache occurring on 15 or more days per month for more than three months a year, which, on at least eight days per month, has the features of migraine without or with aura [6]. The overall prevalence of CM ranges from $1.4 \%$ to $2.2 \%$ of the general population, which reflects $8 \%$ of all individuals suffering from migraine $[7,8]$. In women, the prevalence of CM peaks at 18-29 years and again at 40-49 years [9]. Chronic migraine in most cases evolves from episodic migraine, with a conversion rate of $2.5 \%$ to $3 \%$ a year [10]. Published studies have demonstrated that onabotulinumtoxin A (ONA-BoNT/A) has a particular effect on the prevention of $\mathrm{CM}$, although the mechanism is not fully understood [11-14]. Recently, new effective therapeutics based on monoclonal antibodies against Calcitonin Gene Related Peptide or its receptor (anti-CGRP-mAbs/CGRP$\mathrm{R}-\mathrm{mAbs}$ ) have been approved. The aim of this review was to assess the position of ONA-BoNT/A among other licensed medications for $\mathrm{CM}$, and to make recommendations on treatment pathways.

Address for correspondence: Izabela Domitrz, Department of Neurology, Faculty of Medical Sciences, Medical University of Warsaw, Cegłowska 80 Str., 01-809 Warsaw, Poland; e-mail: izabela.domitrz@wum.edu.pl

Received: 23.03.2021 Accepted: 9.07.2021 Early publication date: 3.09.2021

This article is available in open access under Creative Common Attribution-Non-Commercial-No Derivatives 4.0 International (CC BY-NC-ND 4.0) license, allowing to download articles and share them with others as long as they credit the authors and the publisher, but without permission to change them in any way or use them commercially. 


\section{Impact of CM on patients' lives}

While neurological disorders as a group are a significant cause of disability and death worldwide [15], migraine, alongside lower-back pain, is associated with the highest number of disability-adjusted life-years (DALYs) [16]. The Global Burden of Disease (GBD) estimates that in 2016 migraine was responsible for 45.1 million years lived with disability (YLDs) $[16,17]$. Migraine, especially CM, has a significant impact on patients' lives in terms of their professional work, social activities and private lives [18]. The social cost of migraine is high for a number of reasons. These include inefficiency at work, reduced functionality, medication use, and outpatient, inpatient and emergency medical visits. The total costs include both direct (medications, visits, examinations), and much higher, indirect costs (absenteeism, presenteeism) resulting in decreased productivity [19]. A very large disproportion between direct costs and indirect costs is visible. Indirect costs are many times greater. In the indirect cost category, the costs of presenteeism are many times greater than the costs of absenteeism. The conclusion is therefore that the primary cost implication of migraine is the cost of significantly reduced productivity. Most people with a migraine attack come to work or develop a migraine attack at work and then carry out their duties and activities with significantly limited productivity. This limitation can result in 50\% performance loss or more. This generates high costs of presenteeism in the group of people suffering from migraines. The estimated annual cost of presenteeism for one person suffering from episodic migraine in Poland is PLN 2,149.22, and the estimated cost of presenteeism for one person suffering from CM is PLN 10,225.14.

The higher cost of presenteeism for people suffering from CM may result not only from migraine attacks, but also from ailments resulting from other diseases. It should be taken into account that the estimated number of economically active people suffering from episodic migraine in Poland exceeds 2 million, and the number of people suffering from CM may exceed 350,000. This means costs in the range of 6-8.5 billion PLNannually, i.e. $0.3-0.4 \%$ of the annual Gross Domestic Product (GDP). An additional problem is the coexistence of migraine with other diseases, including mental, neurological, vascular and cardiological disorders [15]. Among psychiatric disorders, depressive disorder (MDD) is the most common disorder observed in patients with migraine [20]. Migraine as an 'almost whole life-lasting' debilitating and disabling disorder has a significant influence on well-being and social/ healthcare system costs [21].

\section{Pharmacoeconomic aspects of chronic migraine}

Pharmacoeconomics is an increasingly important part of the evaluation of migraine therapies [22,23]. Taking into account the therapeutic approach before the era of
ONA-BoNT/A and anti-CGRP-mAbs/anti-CGRP-R-mAbs, such costs related to hospitalisations/ED visits, healthcare provider visits, procedures and medications in chronic migraineurs are globally three times as much as in patients with episodic migraine. In the USA, the aforementioned mean annual sub-costs of chronic migraine are as follows: $\$ 86.7, \$ 498.4$, $\$ 557.1$, and $\$ 3,002.4$, with a mean total annual cost of $\$ 4,144$, and $\$ 187.2, \$ 178, \$ 127.3$, and $\$ 1,040.4$ in episodic migraine respectively, with a mean total annual cost of $\$ 1,533$ [24]. In Canada, as well as in European countries, the proportions between the mean costs of treatment of chronic migraine and episodic migraine are similar [23, 24]. According to the data of the Social Insurance Institution, in 2017, 97,349 sick leave days due to migraine were financed in Poland [25]. It follows that the costs of sickness absenteeism were four times higher than the direct medical costs incurred by the taxpayer in 2017 .

\section{CM treatment - review of recommendations}

Current recommendations developed by the European Neurological Society and the American Academy of Neurology, as well as the International Headache Society, include traditional medication and complementary drug treatments. It has been estimated that c.40\%people with migraine would benefit from preventive therapy, but with chronic one probably less than $65 \%$. Unfortunately, about half of those who would be candidates for preventive treatment are prescribed prophylactic treatment instead $[26,27]$.

Drugs that have the strongest evidence supporting their effectiveness as chronic migraine prevention (category A evidence) include antiepileptic drugs (valproate and topiramate). According to the European Medicines Agency (EMA) recommendations, valproic acid should not be used in women with childbearing potential (US Food and Drug Administration (FDA) Category X) $[28,29]$. Amitriptyline is probably effective as a preventive in $\mathrm{CM}$ (category $\mathrm{B}$ evidence). In the recommendations (level A/B) for CM, ONA-BoNT/A was considered a drug with well-documented effectiveness in a placebo-controlled clinical trials [30]. Monoclonal anti-CGRP antibodies (mAbs-CGRP) are a new therapeutic option for CM. Like ONA-BoNT/A, they show a good adherence profile as they are injected once a month or once a quarter. The safety profile and tolerability of both ONA-BoNT/A and anti-CGRP/CGRP-R $\mathrm{mAbs}$ are excellent and comparable, with good compliance and adherence to these therapies. Moreover, they both act in patients who have experienced previous treatment failures, in patients with $\mathrm{MOH}$, and in individuals with concomitant depression and/or anxiety, having an additional benefit in the latter.

The results from randomised, placebo-controlled trials (RCT) are additionally confirmed by real-world studies (RWS) discussed in this paper. Substantial studies which have been published on $\mathrm{mAbs}$ against CGRP/CGRP-R locate this class of therapeutics in a very strong position in the options for the treatment of migraine. 


\section{Possible mode of action of ONA-BoNT/A in migraine}

The analgesic effect of ONA-BoNT/A has been shown in cervical dystonia, where pain relief precedes the muscular effect. Therefore, it is not only due to muscle relaxation, but probably also due to sensory nerves involvement [31]. Nevertheless, the possible mode of action of ONA-BoNT/A in migraine is not yet fully understood.

There are several different mechanisms underlying this effect, such as axonal transport and transcytosis, inhibition of key neurotransmitters release, and modulation of receptors and chronic inflammation [32]. The majority of studies showing these possible mechanisms are based on animal models. The pretreatment of a skin area with ONA-BoNT/A injection in a capsaicin pain model reduced the trigeminal pain intensity, secondary hyperalgesia, blood flow and skin temperature compared to normal saline [33]. ONA-BoNT/A retrograde transport to the central nervous system has been proven, and colchicine, an axonal transport blocker, is able to inhibit this effect. In a formalin model, unilateral and contralateral injections decreased pain showing both peripheral and central desensitisation effects. Peripheral scalp injections may therefore result in retrograde transportation through the connections (skull sutures) to the meninges, Gasserian trigeminal ganglion and occipital nerves through dorsal roots to the cervical spine [32-34].

The protocol for migraine treatment with ONA-BoNT/A injections utilises this proximity of trigeminal and occipital nerves endings [32]. Several animal studies show that ONABoNT/A also inhibits the release of a number of neurotransmitters associated with migraine such as CGRP and substance P (SP), serotonin, glutamate, gamma aminobutyric acid (GABA), noradrenaline, dopamine, enkephalin and glycine. CGRP has a crucial role in peripheral and central sensitisation in migraine. Due to the retrograde ONA-BoNT/A transportation, these effects may be both peripheral and central $[32,35]$.

ONA-BoNT/A blocking peripheral neurotransmitter release may result in peripheral sensitisation of nociceptors. A consequence of this would be an indirect reduction of central sensitisation as well [36]. ONA-BoNT/A has been shown to inhibit the surface expression of numerous nociceptive receptors such as TRPV1, TRPM8, TRPA1, P2X3, and GABA-A, and is an agonist of $\mu$-opioid receptors. The last one agonistic opioid effect diminishes the pain, but the mechanism how ONABoNT/A may block $\mu$-opioid receptors remains unknown. TRP channels activation resulting in the release of both CGRP and SP, and therefore this inhibition effect of ONA-BoNT/A may theoretically decrease this effect. A clinical trial of a TRPV1 antagonist in acute migraine showed it was ineffective, but it was not tested in chronic migraine patients [32].

The release of CGRP during neuronal activation of the trigeminal system stimulates the satellite glia cells, which in turn release proinflammatory cytokines, thereby further modulating the neuronal response. This process is believed to participate in the maintenance of chronic migraine [37]. ONA-BoNT/A downregulates pronociceptive interleukins IL-1 $\beta$ and IL-18 in the dorsal root ganglion, and upregulates antinociceptive interleukins IL-1RA and IL-10 in the spinal cord $[28,32,38]$. This may explain why ONA-BoNT/A is so effective in chronic, but not episodic, migraine or in tension type headaches.

The mechanisms of BoNT/A in chronic migraine are still unclear and a uniform concept is not yet possible, but they have translated successfully into clinical trials with ONA-BoNT/A in patients with chronic migraine.

\section{Randomised clinical studies of ONA-BoNT/A in treatment of CM}

The PREEMPT-2 trial was the first to prove good efficacy and safety of ONA-BoNT/A in the preventive therapy of CM [39]. The rationale underlying the concept of multiple administrations of the medication over 31-39 injection-points, of $5 \mathrm{U}$ each, was derived from the hypothetical suppressive/ inhibitory effect of ONA-BoNT/A on the release of neurotransmitters within the nociceptive pathways in the brain and the dura mater, presumably in peptidergic neurons containing calcitonin gene-related peptide (CGRP). The injections were made in the vicinity of five groups of muscles, in the frontal, temporal, parieto-occipital areas of the skull, the area of the paraspinal muscles of the upper neck, and the region of the upper part of the trapezius muscles. The minimum number of injection-sites was 31, and there were up to eight optional, additional injections to be given in a 'follow-the-pain' mode. In pooled analysis from Part 1 and Part 2 of the PREEMPT study, the primary goal and the secondary goal were achieved. These included fewer monthly headache days, monthly migraine days, monthly moderate and severe headache days, monthly cumulative number of hours with headache, and number of triptans taken. The only parameter which initially failed (due to an incorrect methodological assumption) was the number of days with abortive drug taken. The differences between the ONA-BoNT/A treatment group and the placebo group were statistically highly significant. Such statistical differences were equally high both in 'pure CM' patients as well as in CM with concomitant Medication Overuse Headache $(\mathrm{MOH})$ individuals.

\section{Long-term open-label observational studies and real-world studies of ONA-BoNT/A in treatment of CM}

The paradigm of injections from the PREEMPT study has become the standard for many subsequent studies, both RCT, and observational, real-world evaluations of this treatment, RWS producing 'real-world data' (RWD). In 2018, the initial results of COMPEL, a real-world study, were published [40]. 
This assessed the impact of ONA-BoNT/A on CM parameters over two years. This model confirmed the high efficacy of the drug previously demonstrated in the PREEMPT trial in terms of reduced headache days per month, and a significant improvement in headache impact on daily activities as assessed by the Headache Impact Test-6 (HIT-6) evaluating the effect of headaches on professional activities, activities at school, housework, as well as social and personal activities. The safety and tolerability of the medication was equally good as in the placebo-controlled study, even though the duration of COMPEL was twice that of PREEMPT. Only a few cases of transient blepharoptosis, local pain, muscle tension, and transient neck pain were reported.

In the PREEMPT trial, there was a slightly higher reduction in headache days after 52 weeks ( 11.7 days) than after 60 weeks of open-label treatment in the COMPEL study (9.2 days). We speculate that this was related to the total dose of the drug, because in the COMPEL trial all patients received a total dose of $155 \mathrm{U}$ into 31 fixed injection points, whereas in the PREEMPT study it was acceptable to administer up to an additional $40 \mathrm{U}$ in a 'follow-the-pain' manner. Thus some patients received as much as 195 U. A higher efficacy of $195 \mathrm{U}$ of ONA-BoNT/A compared to $155 \mathrm{U}$ was demonstrated in another open-label trial [38]. The better effect of a $195 \mathrm{U}$ dose compared to a $155 \mathrm{U}$ dose was shown not only in reducing headache days per month, but also in reducing migraine days a month, and in HIT-6 score Extended results of COMPEL study focused on co-morbidities of CM as depression, anxiety and sleep disorders [41].

In other studies, CM is associated with depression and anxiety in a high proportion of patients: in $41 \%$ and $30 \%$ [42] or even as high as $47 \%$ and $58 \%$ respectively [44]. Also, the risk of developing major depression within two years in migraine patients is more than five times greater than in the population without migraine [45]. This issue was addressed in the open-label REPOSE study [46], which demonstrated a statistically significant trend towards a reduction of the total score of health state self-perception (EQ-5D), which also included symptoms of depression and anxiety in CM patients treated for two years with ONA-BoNT/A. Similar findings were found in the COMPEL study: compared to the baseline, in week 108 of ONA-BoNT/A treatment using the $155 \mathrm{U}$ dose, $78 \%$ of migraine patients experienced a significant reduction in depression symptoms when assessed by the PHQ-9 questionnaire [42]. At the same time $81.5 \%$ of those patients showed a significant decrease in anxiety symptoms measured by the GAD-7 test. The effect of ONA-BoNT/A treatment on depression symptoms increased over the course of the therapy, being present in $61.8 \%$ of patients after 12 weeks, in $66.8 \%$ after 48 weeks, and in up to $78 \%$ after 108 weeks. This applied to patients with mild, moderate, moderate-to-severe and severe depression symptoms. Anxiety symptoms, mild, moderate and severe, also improved at the same study points: after 12 weeks in $69.3 \%$, after 48 weeks in $78 \%$, and after 108 weeks in up to $81.5 \%$.
In the COMPEL study, a reduction in depression symptoms was observed in all patients: in those with a reduction in headache days of at least $50 \%$, in those with a reduction of headache days of at least $25 \%$, and in those who did not respond to treatment (i.e. with an improvement of less than $25 \%)$. However, after 48 weeks of treatment of patients with a reduction in the frequency of headache days of at least $50 \%$, improvement in depression and anxiety was significantly higher than in patients without response in headaches of at least 50\%. A similar phenomenon with regard to non-responders was observed in the group achieving reduction of headache days of at least $25 \%$ [42].

In recent years, there have been a number of long-term clinical evaluations of ONA-BoNT/A effect in the treatment of CM, most of which were not RCT, but RWD i.e. observational studies. In the meta-analysis published by Tassorelli et al. in 2018 [45], the data presented came from five studies lasting 18-48 months, in which $\mathrm{MOH}$ was present in a substantial proportion or even in $100 \%$ of patients. All studies proved the significant effectiveness of ONA-BoNT/A in CM, including when it is complicated by $\mathrm{MOH}$. In several RWD publications with ONA-BoNT/A in CM from single centres or single countries (Italy, Greece, Australia), the data obtained has shown comparable improvements in terms of fewer monthly days with headaches, and/or number of days with moderate to severe headaches, and/or monthly mean hours with headaches [46-50]. The numbers of $50 \%$ responders or $75 \%$ responders progressively increased over the course of long therapies. Consequently, the number of abortive drugs taken because of headaches, including migraine, also decreased over the course of treatment with ONA-BoNT/A [46-50]. Concomitantly to clinical improvement achieved over long therapies, questionnaires evaluating quality of life (HIT, MIDAS) have revealed parallel improvements $[47,49,50]$.

Apart from the clearly beneficial effect of ONA-BoNT/A on the prevention of headaches in CM, some of the above-mentioned studies have also found its effect on abortive treatment. This is pronounced by progressive shortening of the latency time between intake of abortive drug (triptan) and the relief of headache $[47,50]$.

\section{Comparison of effectiveness of ona-bont/a and anti-CGRP monoclonal antibodies in treatment of CM}

Four monoclonal antibodies for migraine therapy have already been developed: one against the CGRP-R (erenumab) and three against the CGRP peptide or ligand (eptinezumab, fremanezumab and galcanezumab).

At present, there are no reliable 'head-to-head' studies comparing the effectiveness of ONA-BoNT/A and monoclonal antibodies (mAbs) anti-CGRP/anti-CGRP-R in the treatment of CM. However, we can expect the first such analyses in the near future: She et al. published in January 2020 in the Journal 
Medicine the protocol they have adopted into their study on the comparison of ONA-BoNT/A and anti-CGRP/CGRP-R antibodies in the prophylactic treatment of $\mathrm{CM}$, which will be a systematic review and meta-analysis of available studies [51].

To date, ONA-BoNT/A in the treatment of CM has only been compared to that of some preventive oral medications. In 2018, a meta-analysis of available studies on the treatment of CM with ONA-BoNT/A was published in the Cochrane database, in which its effectiveness was successfully compared to a placebo, and, for non-inferiority, to comparators comprising valproic acid, topiramate and histamine, showing also better safety and tolerability profiles than oral prophylactics [52].

Clinical trials have shown that all four CGRP/CGRP-R mAbs have a favourable safety and tolerability profile, as well as high efficacy, and they are recommended for the treatment of episodic migraine with frequent attacks ( $>4$ pain days per month) as well as CM [53]. In all studies, mAbs has demonstrated greater efficacy in reducing the number of migraine days per month compared to placebo, a higher proportion of patients with at least a $50 \%$ reduction in the number of migraine days, and a significant reduction in the number of abortive medications used.

The efficacy of erenumab in CM has been assessed in a Phase II study which compared doses of $70 \mathrm{mg}$ and $140 \mathrm{mg}$ administered subcutaneously every month. Both doses achieved a statistically significant difference in the reduction of migraine days compared to the placebo group, which was 2.5 days. The endpoint of at least $50 \%$ reduction of migraine/headache days was achieved by $40 \%$ of patients receiving erenumab at a dose of $70 \mathrm{mg}$, and by $41 \%$ of patients receiving erenumab at a dose of $140 \mathrm{mg}$ [54]. Tepper et al. continued to evaluate the effectiveness of both doses of erenumab in a long-term, 52-week, open-label study [53]. Clinically significant reductions from the double-blind treatment phase baseline (about half) were observed for monthly migraine days and migraine-specific medication days. Achievement of $50 \%, 75 \%$ and $100 \%$ reductions from the double-blind treatment phase baseline in monthly migraine days at week 52 were reported by $59.0 \%, 33.2 \%$ and $8.9 \%$ of patients, respectively. A numerically greater benefit was observed with $140 \mathrm{mg}$ compared to $70 \mathrm{mg}$ at weeks 52 [55]. In patients with $\mathrm{CM}, 12$ weeks of treatment with fremanezumab at doses of $225 \mathrm{mg}$ monthly and $675 \mathrm{mg}$ quarterly was associated with a significant decrease in the mean number of migraine days (difference from placebo was 1.8 and 1.7 days, respectively) and a decrease in the number of headache days (difference from placebo of 2.1 and 1.8 days). There was no benefit of the higher dose administered every three months over monthly injections of the lower dose [56]. The efficacy of eptinezumab in the treatment of CM was analysed for $100 \mathrm{mg}$ and $300 \mathrm{mg}$ doses administered intravenously every quarter. There was a statistically significant difference in the reduction in the number of migraine days, 2.0 and 2.6 days respectively, in patients receiving the $100 \mathrm{mg}$ and $300 \mathrm{mg}$ doses. A minimum
$50 \%$ reduction in symptoms in the 12 th week of therapy was recorded in $57.6 \%$ and $61.4 \%$ of patients treated with eptinezumab at doses of $100 \mathrm{mg}$ and $300 \mathrm{mg}$, respectively [57]. In patients with CM, 12 weeks of treatment with galcanezumab at doses of $120 \mathrm{mg}$ or $240 \mathrm{mg}$ per month was associated with a significant decrease in the average number of migraine days, on average by 2.1 and 1.9 days compared to the placebo group, and a higher percentage of patients with an at least 50\% reduction in the number of migraine days: $27.6 \%$ vs. $15.4 \%$ [58]. The effectiveness of fremanezumab and erenumab has also been assessed in CM that was refractory to previous pharmacological treatment. Fremanezumab, in the 12th week of treatment, showed a significant reduction in the number of days with migraine compared to placebo (3.2 days and 3.8 days in relation to the doses of $675 \mathrm{mg}$ quarterly and $225 \mathrm{mg}$ monthly) [59]. Treatment with erenumab following previous treatment failures was associated with an average of 4.7 days reduction in the number of migraine days [60]. A summary of the effectiveness of anti-CGRP antibodies is set out in Table 2.

\section{Conclusions}

Data obtained from RCT and RWD suggests that ONABoNT/A effectively reduces the frequency of migraine days, of headache days and the total number of hours with headaches in patients with CM. It is currently recommended to apply treatment with ONA-BoNT/A also to CM patients with concomitant medication overuse headache.

With regard to the original RCT PREEMPT study (along with a number of RWD reports following the PREEMPT study), it can be concluded that:

- Long-term (up to four years) treatment of CM with ONABoNT/A is safe, well tolerated, and effectively decreases the number of headache days per month compared to baseline.

- Numeric values show comparable, and in some studies even better, effect of ONA-BoNT/A if used in RWS conditions than in RCT.

- In all reported RWS, significant clinical improvements in relation to baseline were observed with regard to: monthly mean reduction of headache days, migraine days, days with moderate to severe headache, and days when abortive drugs were used.

- A 195 U dose administered in 'real world' conditions over two years according to the paradigm used in the PREEMPT study seems slightly more efficacious than a $155 \mathrm{U}$ dose.

- Numerous trials have also demonstrated significant improvements during 2-4 years of treatment in the perceived negative impact of $\mathrm{CM}$ on selected parameters of quality of life, especially on activities associated with work, education, housework, social activities and personal lives.

- In addition to the beneficial effect on migraine headaches, ONA-BoNT/A has a favourable impact on the reduction of concomitant symptoms of depression and anxiety, 
Table 1. Summary of most important results ('end-points') of several RWD outcomes compared to PREEMPT study as standard RCT trial with ONA-BoNT/A in CM. Data presented as mean change in 28-day treatment vs. baseline

\begin{tabular}{|c|c|c|c|c|c|c|c|c|}
\hline \multirow[t]{2}{*}{ End point } & \multicolumn{3}{|l|}{ RCT } & \multicolumn{4}{|c|}{ RWD } & \multirow[b]{2}{*}{$\begin{array}{l}\text { Vikelis } \\
2019\end{array}$} \\
\hline & PREEMPT & COMPEL & REPOSE & $\begin{array}{c}\text { Dikmen } \\
2018\end{array}$ & $\begin{array}{c}\text { Negro } \\
2016\end{array}$ & $\begin{array}{c}\text { Santoro } \\
2019\end{array}$ & $\begin{array}{l}\text { Stark } \\
2019\end{array}$ & \\
\hline Mean change in headache days & $-8,4$ & $-7,4$ & $-8,0$ & $-13,0$ & $-12,0$ & $-14,4$ & $-14,7$ & -13.6 \\
\hline Mean change of migraine days & $-8,2$ & - & - & - & $-11,9$ & - & $-9,4$ & - \\
\hline $\begin{array}{l}\text { Mean change of moderate/ } \\
\text { /severe headache days }\end{array}$ & $-7,7$ & $-6,5$ & - & - & - & - & - & $-8,2$ \\
\hline Mean change of HIT- 6 score & 4,8 & - & - & - & $-6,9$ & - & $-11,8$ & - \\
\hline Mean change of days with abortive drugs & $-10,1$ & - & - & - & $-11,1$ & - & $-11,8$ & $-11,0$ \\
\hline
\end{tabular}

The data presented as the mean change $\ln 28$ day treatment vs. baseline. With courtesy of Allergan

Table 2. Summary of effectiveness of anti-CGRP/CGRP-R antibodies in CM

\begin{tabular}{|c|c|c|c|c|c|}
\hline Author & $\begin{array}{l}\text { Indication/ } \\
\text { /phase }\end{array}$ & Medication/dose & Comparator & $\begin{array}{l}\text { MMD difference } \\
\text { ( } p \text { value) }\end{array}$ & $\begin{array}{l}\text { MHD difference } \\
\text { (p value) }\end{array}$ \\
\hline Tepper et al. 2017 & $\begin{array}{l}\text { CM } \\
\text { Phase II }\end{array}$ & $\begin{array}{l}\text { Erenumab } \\
70 \text { mg monthly } \\
140 \text { mg monthly }\end{array}$ & Placebo & $\begin{array}{l}-2.5(<0.0001) \\
-2.5(<0.0001)\end{array}$ & $\begin{array}{l}-2.2(<0.0001) \\
-2.3(<0.0001)\end{array}$ \\
\hline Tepper et al. 2020 & $\begin{array}{l}\text { CM } \\
\text { Open-label }\end{array}$ & $\begin{array}{l}\text { Erenumab } \\
70 \text { mg monthly } \\
140 \text { mg monthly }\end{array}$ & - & $\begin{array}{l}-8.5 \\
-10.5\end{array}$ & Not evaluated \\
\hline Silberstein et al. 2017 & $\begin{array}{l}\text { CM } \\
\text { Phase III }\end{array}$ & $\begin{array}{l}\text { Fremanezumab } \\
225 \text { mg monthly } \\
675 \text { mg quarterly }\end{array}$ & Placebo & $\begin{array}{l}-1.8(<0.001) \\
-1.7(<0.001)\end{array}$ & $\begin{array}{l}-2.1(<0.001) \\
-1.8(<0.001)\end{array}$ \\
\hline Detke et al. 2018 & $\begin{array}{l}\text { CM } \\
\text { Phase III }\end{array}$ & $\begin{array}{l}\text { Galcanezumab } \\
120 \text { mg monthly } \\
240 \text { mg monthly }\end{array}$ & Placebo & $\begin{array}{l}-2.1(<0.001) \\
-1.9(<0.001)\end{array}$ & $\begin{array}{l}-1.8(<0.001) \\
-1.6(<0.001)\end{array}$ \\
\hline Lipton et al. $\backslash 2020$ & $\begin{array}{l}\text { CM } \\
\text { Phase III }\end{array}$ & $\begin{array}{l}\text { Eptinezumab } \\
100 \text { mg quarterly } \\
300 \text { mg quarterly }\end{array}$ & Placebo & $\begin{array}{l}-2.0(<0.0001) \\
-2.6(<0.0001)\end{array}$ & $\begin{array}{l}-1.7 \\
-2.3\end{array}$ \\
\hline Ferrari et al. 2019 & $\begin{array}{l}\text { refractory EM, CM } \\
\text { Phase IIIb }\end{array}$ & $\begin{array}{l}\text { Fremanezumab } \\
225 \text { mg monthly } \\
675 \text { mg quarterly }\end{array}$ & Placebo & $\begin{array}{l}-3.8 \text { (CM group) } \\
-3.2 \text { (CM group) }\end{array}$ & Not evaluated \\
\hline Raffaeli et al. 2020 & $\begin{array}{l}\text { refractory CM } \\
\text { Open trial }\end{array}$ & $\begin{array}{l}\text { Erenumab } \\
70 \text { mg monthly }\end{array}$ & - & -4.7 & Not evaluated \\
\hline
\end{tabular}

MHD - mean headache days; MMD — mean migraine days

irrespective of whether or not the patient has achieved a satisfactory reduction in headache days. This phenomenon, however, is more pronounced in patients who have achieved a good effect in terms of frequency of headaches, and more significant reductions are observed with increasing treatment durations. An alternative explanation, however, takes into consideration the direct effect of ONABoNT/A on depression and anxiety $[61,62]$.

A summary of the most important results ('end-points') of several RWD outcomes compared to the PREEMPT study as the standard RCT trial with ONA-BoNT/A in CM is shown below in Table 1 .

NICE (The National Institute for Health and Care Excellence) recommends the use of ONA-BoNT/A to treat CM that has not responded to at least three prior pharmacological prophylactic therapies [63]. A similar approach in the treatment of CM in regard to ONA-BoNT/A is recommended by the Polish Headache Society [64].

Thus today we believe that it is not justified to position ONA-BoNT/A in relation to CGRP/CGRP-R, or to recommend one of them being used ahead of the other. However, taking into account the pharmacoeconomic aspects, NICE suggests the use of ONA-BoNT/A first and, if it fails, then to try mAbs.

According to this consensus, therapy with ONA-BoNT/A and CGRP/CGRP-R $m A$ bs should not be combined. In patients with $\mathrm{CM}$ treated with ONA-BoNT/A with inadequate treatment response, it is suggested to stop onabotulinumtoxinA before the initiation of $\mathrm{mAbs}$ [53]. However, a growing number of reports suggest the beneficial effect of combined therapy. The dual mechanisms of both medication actions seem to offer a greater chance of controlling CM [65]. 
To sum up, ONA-BoNT/A is an effective treatment for $\mathrm{CM}$, the position of which is defined as level $\mathrm{A}$, and it might be considered as a first-line therapy in CM.

Ethical permission: Ethical approval was not necessary for this study.

Funding: None.

Conflict of the interest: ID has served as an expert on Advisory Boards and as a lecturer for the following companies: Allergan, Novartis, Teva, Elli Lily;

ASł has served as an expert on Advisory Boards and as a lecturer for the following companies: Allergan, Novartis, Teva, Sanofi, Biogen, Boehringer Ingelheim, Bayer;

JS has contracted advisory boards, consultations and lectures for Allergan, Ipsen, Merz, Novartis and Teva;

MBJ has contracted advisory boards, consultations and lectures for Allergan Abbvie, Merz, Novartis and Teva;

ASt has served as an expert on Advisory Boards and as a lecturer for the following companies: Allergan, Abbvie, Novartis, Teva, Elli Lily;

KR has served as an expert on Advisory Boards and as a lecturer for the following companies: Allergan, Abbvie, Novartis, Teva;

JG declared no conflict;

JJR has served as an expert on Advisory Boards and as a lecturer for the following companies: Allergan, Abbvie, Novartis, Teva, Elli Lily.

\section{References}

1. Linde M, Gustavsson A, Stovner L, et al. The cost of headache disorders in Europe: the Eurolight project. Eur J Neurol. 2012; 19(5): 703-711, doi: 10.1111/j.1468-1331.2011.03612.x, indexed in Pubmed: 22136117.

2. GBD 2015 Disease and Injury Incidence and Prevalence Collaborators. Global, regional, and national incidence, prevalence, and years lived with disability for 310 diseases and injuries, 1990-2015: a systematic analysis for the Global Burden of Disease Study 2015. Lancet. 2016; 388(10053): 1545-1602, doi: 10.1016/S0140-6736(16)31678-6, indexed in Pubmed: 27733282.

3. Chądzyński P, Kacprzak A, Domitrz W, et al. Migraine headache facilitators in a population of Polish women and their association with migraine occurrence - preliminary results. Neurol Neurochir Pol. 2019; 53(5): 377-383, doi: 10.5603/PJNNS.a2019.0044, indexed in Pubmed: 31592536.

4. Begasse de Dhaem O, Gharedaghi MH, Bain P, et al. Identification of work accommodations and interventions associated with work productivity in adults with migraine: A scoping review. Cephalalgia. 2021; 41(6): 760-773, doi: 10.1177/0333102420977852, indexed in Pubmed: 33302697.

5. Linde M, Mulleners WM, Chronicle EP, et al. Antiepileptics other than gabapentin, pregabalin, topiramate, and valproate for the prophylaxis of episodic migraine in adults. Cochrane Database Syst Rev. 2013; 2013(6): CD010608, doi: 10.1002/14651858.CD010608, indexed in Pubmed: 23797674.

6. https://ichd-3.org/1-migraine/1-3-chronic-migraine.
7. Pozo-Rosich P, Coppola G, Pascual J, et al. How does the brain change in chronic migraine? Developing disease biomarkers. Cephalalgia. 2021; 41(5): 613-630, doi: 10.1177/0333102420974359, indexed in Pubmed: 33291995.

8. Natoli JL, Manack A, Dean B, et al. Global prevalence of chronic migraine: a systematic review. Cephalalgia. 2010; 30(5): 599-609, doi: 10.1111/j.1468-2982.2009.01941.x, indexed in Pubmed: 19614702.

9. Buse DC, Manack AN, Fanning KM, et al. Chronic migraine prevalence, disability, and sociodemographic factors: results from the American Migraine Prevalence and Prevention Study. Headache. 2012; 52(10): 1456-1470, doi: 10.1111/j.1526-4610.2012.02223.x, indexed in Pubmed: 22830411.

10. May A, Schulte L. Chronic migraine: risk factors, mechanisms and treatment. Nature Reviews Neurology. 2016; 12(8): 455-464, doi: 10.1038/nrneurol.2016.93.

11. Gazerani P, Staahl C, Drewes AM, et al. The effects of Botulinum Toxin type A on capsaicin-evoked pain, flare, and secondary hyperalgesia in an experimental human model of trigeminal sensitization. Pain. 2006; 122(3): 315-325, doi: 10.1016/j.pain.2006.04.014, indexed in Pubmed: 16677761.

12. Mazzocchio R, Caleo M. More than at the neuromuscular synapse: actions of botulinum neurotoxin $A$ in the central nervous system. Neuroscientist. 2015; 21(1): 44-61, doi: 10.1177/1073858414524633, indexed in Pubmed: 24576870.

13. Shen B, Wang L. Impact of the botulinum-A toxin on prevention of adult migraine disorders. J Integr Neurosci. 2020; 19(1): 201-208, doi: 10.31083/j.jin.2020.01.1240, indexed in Pubmed: 32259898.

14. Herd CP, Tomlinson CL, Rick C, et al. Cochrane systematic review and meta-analysis of botulinum toxin for the prevention of migraine. BMJ Open. 2019; 9(7): e027953, doi: 10.1136/bmjopen-2018-027953, indexed in Pubmed: 31315864.

15. GBD 2016 Neurology Collaborators. Global, regional, and national burden of neurological disorders, 1990-2016: a systematic analysis for the Global Burden of Disease Study 2016. Lancet Neurol. 2019; 18(5): 459-480, doi: 10.1016/S1474-4422(18)30499-X, indexed in Pubmed: 30879893.

16. GBD 2016 Neurology Collaborators, GBD 2016 Headache Collaborators. Global, regional, and national burden of migraine and tension-type headache, 1990-2016: a systematic analysis for the Global Burden of Disease Study 2016. Lancet Neurol. 2018; 17(11): 954-976, doi: 10.1016/S1474-4422(18)30322-3, indexed in Pubmed: 30353868.

17. Saylor D, Steiner TJ. The global burden of headache. Semin Neurol. 2018; 38(2): 182-190, doi: 10.1055/s-0038-1646946, indexed in Pubmed: 29791944.

18. Lyngberg AC, Rasmussen BK, Jørgensen T, et al. Incidence of primary headache: a Danish epidemiologic follow-up study. Am J Epidemiol. 2005; 161(11): 1066-1073, doi: 10.1093/aje/kwi139, indexed in Pubmed: 15901627.

19. Społeczne znaczenie migreny z perspektywy zdrowia publicznego i systemu ochrony zdrowia. Opracowanie: Zakład Analiz Ekonomicznych i Systemowych Narodowy Instytut Zdrowia Publicznego -Państwowy Zakład Higieny, 2018. https://www.pzh.gov.pl/wp-content/uploads/2019/06/RAPORT-MIGRENA-ca\%C5\%82y.pdf.

20. Bigal ME, Lipton RB. The epidemiology, burden, and comorbidities of migraine. Neurol Clin. 2009; 27(2): 321-334, doi: 10.1016/j. ncl.2008.11.011, indexed in Pubmed: 19289218.

21. Jette N, Patten S, Williams J, et al. Comorbidity of migraine and psychiatric disorders-a national population-based study. Headache. 2008; 
48(4): 501-516, doi: 10.1111/j.1526-4610.2007.00993.x, indexed in Pubmed: 18070059.

22. Rapoport AM, Adelman JU. Cost of migraine management: a pharmacoeconomic overview. Am J Manag Care. 1998; 4(4): 531-545, indexed in Pubmed: 10179912.

23. Walley T. Pharmacoeconomics for migraine and headache researchers: basic concepts, methods and terminology. The Journal of Headache and Pain. 2004; 5(4): 217-223, doi: 10.1007/s10194-0040129-y.

24. Stokes M, Becker WJ, Lipton RB, et al. Cost of health care among patients with chronic and episodic migraine in Canada and the USA: results from the International Burden of Migraine Study (IBMS). Headache. 2011; 51(7): 1058-1077, doi: 10.1111/j.1526-4610.2011.01945.x, indexed in Pubmed: 21762134.

25. Bloudek LM, Stokes M, Buse DC, et al. Cost of healthcare for patients with migraine in five European countries: results from the International Burden of Migraine Study (IBMS). J Headache Pain. 2012; 13(5): 361-378, doi: 10.1007/s10194-012-0460-7, indexed in Pubmed: 22644214.

26. Portal Statystyczny ZUS. https://www.zus.pl/baza-wiedzy/statystyka.

27. Domitrz I, Lipa A, Rożniecki J, et al. Treatment and management of migraine in neurological ambulatory practice in Poland by indicating therapy with monoclonal anti-CGRP antibodies. Neurol Neurochir Pol. 2020; 54(4): 337-343, doi: 10.5603/PJNNS.a2020.0054, indexed in Pubmed: 32687594.

28. Domitrz I, Lipa A, Rożniecki J, et al. Migraine diagnosis and treatment in Poland: survey of primary care practitioners. Neurol Neurochir Pol. 2021 [Epub ahead of print], doi: 10.5603/PJNNS.a2021.0045, indexed in Pubmed: 34132385.

29. FDA Drug Safety Communication. Children born to mothers who took valproate products while pregnant may have impaired cognitive development. https://www.fda.gov/Drugs/DrugSafety/ucm261543.htm (October 26, 2018).

30. Product Information: Depakote Oral Tablets, Divalproex Sodium Oral Tablets. AbbVie Inc.

31. Aurora SK, Dodick DW, Turkel CC, et al. OnabotulinumtoxinA for treatment of chronic migraine: Results from the double-blind, randomized, placebo-controlled phase of the PREEMPT 1 trial. Cephalalgia. 2010; 30(7): 793-803, doi: 10.1177/0333102410364676.

32. Matak I, Bölcskei K, Bach-Rojecky L, et al. Mechanisms of Botulinum Toxin type A action on pain. Toxins (Basel). 2019; 11(8), doi: 10.3390/ toxins11080459, indexed in Pubmed: 31387301.

33. Do TP, Hvedstrup J, Schytz HW. Botulinum toxin: A review of the mode of action in migraine. Acta Neurol Scand. 2018; 137(5): 442-451, doi: 10.1111/ane.12906, indexed in Pubmed: 29405250.

34. Ramachandran R, Yaksh TL. Therapeutic use of botulinum toxin in migraine: mechanisms of action. Br J Pharmacol. 2014; 171(18): 4177 4192, doi: 10.1111/bph.12763, indexed in Pubmed: 24819339.

35. Luvisetto S, Gazerani P, Cianchetti C, et al. Botulinum Toxin type a as a therapeutic agent against headache and related disorders. Toxins (Basel). 2015; 7(9): 3818-3844, doi: 10.3390/toxins 7093818, indexed in Pubmed: 26404377.

36. Szok D, Csáti A, Vécsei L, et al. Treatment of chronic migraine with onabotulinumtoxinA: Mode of action, efficacy and safety. Toxins (Basel). 2015; 7(7): 2659-2673, doi: 10.3390/toxins7072659, indexed in Pubmed: 26193319.

37. Gazerani P, Pedersen N, Staahl C, et al. Subcutaneous ONA-BoNT/A type $A$ reduces capsaicin-induced trigeminal pain and vasomotor reactions in human skin. Pain. 2009; 141(1-2): 60-69, doi: 10.1016/j. pain.2008.10.005, indexed in Pubmed: 19004549.
38. Tajti J, Kuris A, Vécsei L, et al. Organ culture of the trigeminal ganglion induces enhanced expression of calcitonin gene-related peptide via activation of extracellular signal-regulated protein kinase 1/2. Cephalalgia. 2011; 31(1): 95-105, doi: 10.1177/0333102410382796, indexed in Pubmed: 20851839.

39. Zychowska M, Rojewska E, Makuch W, et al. Participation of pro- and anti-nociceptive interleukins in botulinum toxin A-induced analgesia in a rat model of neuropathic pain. European Journal of Pharmacology. 2016; 791: 377-388, doi: 10.1016/j.ejphar.2016.09.019.

40. Diener HC, Dodick DW, Aurora SK, et al. PREEMPT 2 Chronic Migraine Study Group. OnabotulinumtoxinA for treatment of chronic migraine: results from the double-blind, randomized, placebo-controlled phase of the PREEMPT 2 trial. Cephalalgia. 2010; 30(7): 804-814, doi: 10.1177/0333102410364677, indexed in Pubmed: 20647171.

41. Blumenfeld AM, Stark RJ, Freeman MC, et al. Long-term study of the efficacy and safety of OnabotulinumtoxinA for the prevention of chronic migraine: COMPEL study. J Headache Pain. 2018; 19(1): 13, doi: 10.1186/s10194-018-0840-8, indexed in Pubmed: 29404713.

42. Negro A, Curto M, Lionetto L, et al. A two years open-label prospective study of OnabotulinumtoxinA $195 \mathrm{U}$ in medication overuse headache: a real-world experience. J Headache Pain. 2015; 17: 1, doi: 10.1186/ s10194-016-0591-3, indexed in Pubmed: 26792662.

43. Blumenfeld AM, Tepper SJ, Robbins LD, et al. Effects of onabotulinumtoxinA treatment for chronic migraine on common comorbidities including depression and anxiety. J Neurol Neurosurg Psychiatry. 2019; 90(3): 353-360, doi: 10.1136/jnnp-2018-319290, indexed in Pubmed: 30630956.

44. Minen MT, Begasse De Dhaem 0, Kroon Van Diest A, et al. Migraine and its psychiatric comorbidities. J Neurol Neurosurg Psychiatry. 2016; 87(7): 741-749, doi: 10.1136/jnnp-2015-312233, indexed in Pubmed: 26733600.

45. Breslau N, Lipton RB, Stewart WF, et al. Comorbidity of migraine and depression: investigating potential etiology and prognosis. Neurology. 2003; 60(8): 1308-1312, doi: 10.1212/01. wnl.0000058907.41080.54, indexed in Pubmed: 12707434.

46. Ahmed F, Gaul C, García-Moncó JC, et al. REPOSE Principal Investigators. An open-label prospective study of the real-life use of onabotulinumtoxinA for the treatment of chronic migraine: the REPOSE study. J Headache Pain. 2019; 20(1): 26, doi: 10.1186/s10194-019-0976-1, indexed in Pubmed: 30845917.

47. Vikelis M, Argyriou AA, Dermitzakis EV, et al. OnabotulinumtoxinA treatment in Greek patients with chronic migraine. J Headache Pain. 2016; 17(1): 84, doi: 10.1186/s10194-016-0676-z, indexed in Pubmed: 27640152.

48. Santoro A, Fontana A, Miscio AM, et al. Quarterly repeat cycles of onabotulinumtoxinA in chronic migraine patients: the benefits of the prolonged treatment on the continuous responders and quality-oflife conversion rate in a real-life setting. Neurol Sci. 2017; 38(10): 1779-1789, doi: 10.1007/s10072-017-3054-y, indexed in Pubmed: 28726049

49. Yalinay Dikmen P, Kosak S, Ilgaz Aydinlar E, et al. A single-center retrospective study of onabotulinumtoxinA for treatment of 245 chronic migraine patients: survey results of a real-world experience. Acta Neurol Belg. 2018; 118(3): 475-484, doi: 10.1007/s13760-018-0978-9, indexed in Pubmed: 29992442.

50. Stark C, Stark R, Limberg N, et al. Real-world effectiveness of onabotulinumtoxinA treatment for the prevention of headaches in adults with chronic migraine in Australia: a retrospective study. J Headache Pain. 2019; 20(1): 81, doi: 10.1186/s10194-019-1030-z, indexed in Pubmed: 31307383. 
51. Santoro A, Copetti M, Miscio AM, et al. Chronic migraine long-term regular treatment with onabotulinumtoxinA: a retrospective real-life observational study up to 4 years of therapy. Neurol Sci. 2020; 41(7): 1809-1820, doi: 10.1007/s10072-020-04283-y, indexed in Pubmed: 32052306.

52. Canlas K, Macalintal-Canlas R, Sakai F. Efficacy of calcitonin generelated peptide antagonists in the treatment of acute migraine: A systematic review and meta-analysis. Acta Medica Philippina. 2019; 53(1), doi: 10.47895/amp.v53i1.223.

53. Herd CP, Tomlinson CL, Rick C, et al. ONA-BoNT/A injections for preventing migraine in adults. Cochrane Database of Systematic Reviews 2018, Issue 6, Art No. : CD011616.

54. Sacco S, Bendtsen L, Ashina M, et al. Correction to: European headache federation guideline on the use of monoclonal antibodies acting on the calcitonin gene related peptide or its receptor for migraine prevention. J Headache Pain. 2019; 20(1): 58, doi: 10.1186/s10194019-0972-5, indexed in Pubmed: 31122188.

55. Tepper S, Ashina M, Reuter U, et al. Safety and efficacy of erenumab for preventive treatment of CM: a randomised, double-blind, placebocontrolled phase 2 trial. Lancet Neurol. 2017; 16(6): 425-34, doi: 10.1016/S1474-4422(17)30083-2, indexed in Pubmed: 28460892.

56. Tepper SJ, Ashina M, Reuter U, et al. Long-term safety and efficacy of erenumab in patients with chronic migraine: Results from a 52-week, open-label extension study. Cephalalgia. 2020; 40(6): 543-553, doi: 10.1177/0333102420912726, indexed in Pubmed: 32216456.

57. Silberstein SD, Dodick DW, Bigal ME, et al. Fremanezumab for the preventive treatment of CM. N Engl J Med. 2017; 377: 2113-22.

58. Lipton R, Goadsby P, Smith J, et al. Efficacy and safety of eptinezumab in patients with chronic migraine. Neurology. 2020; 94(13): e1365e1377, doi: 10.1212/wnl.0000000000009169.
59. Detke HC, Goadsby PJ, Wang S, et al. Galcanezumab in CM. The randomized, double-blind, placebo-controlled REGAIN study. Neurology. 2018 Dec 11. ; 91(24): e2211-e2221.

60. Ferrari $M$, Diener $H$, Ning $X$, et al. Fremanezumab versus placebo for migraine prevention in patients with documented failure to up to four migraine preventive medication classes (FOCUS): a randomised, double-blind, placebo-controlled, phase $3 \mathrm{~b}$ trial. The Lancet. 2019; 394(10203): 1030-1040, doi: 10.1016/s01406736(19)31946-4.

61. Raffaelli B, Kalantzis R, Mecklenburg J, et al. Erenumab in chronic migraine patients who previously failed five first-line oral prophylactics and onabotulinumtoxinA: A dual-center retrospective observational study. Frontiers in Neurology. 2020; 11, doi: 10.3389/ fneur.2020.00417.

62. Wollmer MA, Magid M, Kruger THC, et al. The use of Botulinum Toxin for treatment of depression. Handb Exp Pharmacol. 2021; 263: 265278, doi: 10.1007/164_2019_272, indexed in Pubmed: 31691857.

63. https://www.nice.org.uk/guidance/ta260/chapter/3-The-manufacturers-submission.

64. Stępień A, Kozubski W, Rożniecki JJ, et al. Migraine treatment recommendations developed by an Expert Group of the Polish Headache Society, the Headache Section of the Polish Neurological Society, and the Polish Pain Society. Neurol Neurochir Pol. 2021; 55(1): 33-51, doi: 10.5603/PJNNS.a2021.0007, indexed in Pubmed: 33507529.

65. Pellesi L, Thien P, Ashina $\mathrm{H}$, et al. Dual therapy with anti-CGRP monoclonal antibodies and ONA-BoNT/A for migraine prevention: is there a rationale? Headache. 2020; 60(6): 1056-1065, doi: 10.1111/ head.13843, indexed in Pubmed: 32437038. 